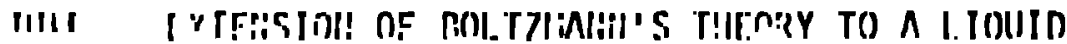

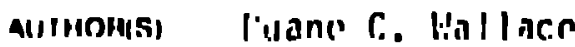

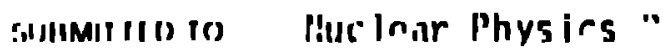

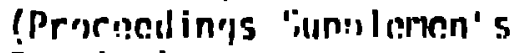

ip.'inn!

\title{
DEscaimas
}

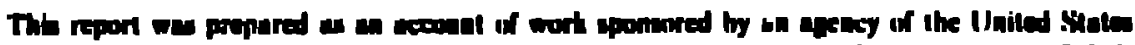

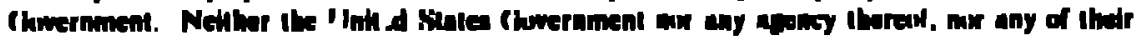

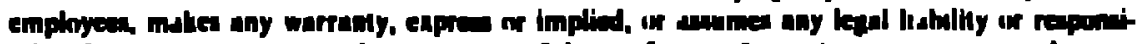

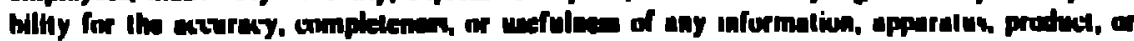

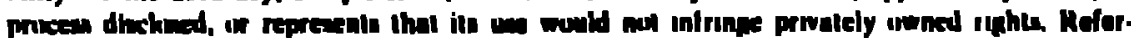

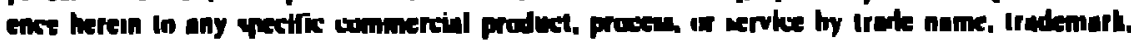

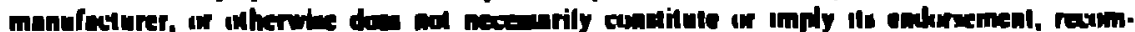

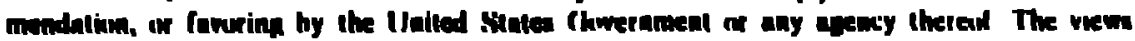

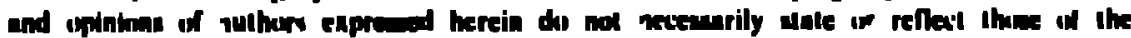

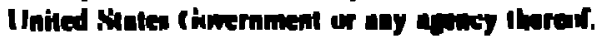

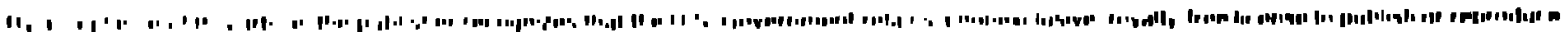

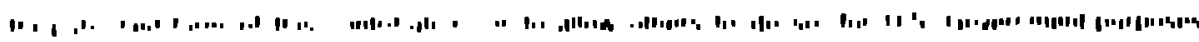

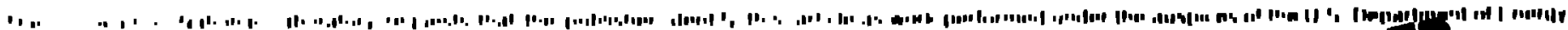




\section{EXTENSION OF BOLTZMANN'S THEORY TO A LIQUID}

\section{Duanr C. WALLACE}

Los A lamos Nationad Laboralory, Los Alamos, New Mexicu 8i545, LSA

A theory for the nonequilibrium statiatical mechavies of a liquid is presented. This thery consisty of coupled evolution equations for the one-particle momentum distribution, and for the two prarticle correlution finction,

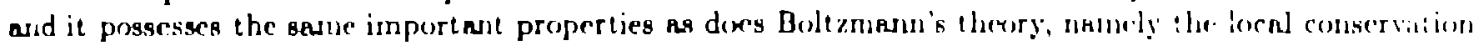
Inws, the local $h$ thenrem, and the correct equilibrium nolution.

\section{INTRODUCTION}

For a gar, the encrgy density is a otntimtical average of the kinetic energy of the particles. The pressure tensor and the encrgy current are adso componsed rn. tirely of kinntic contributions. The important atatistical function, from which all densitien and currents call be calculated, is the one-partirle momentum distribu. tion. In 1872, Bolezmamn' construeted an cquition describing the irreversible cvolution of the momentum diatribution for a nonrouibibriun gar. In this renm" tion, irserersibility arime from the collision integral,

which is a statistical repremetation of two pas cirle col. limions.

For a liquid, the densition nud currenta contuin, in addition to kinctic contributions, potentind contribu tions an well, due to the potentind of interartion be eweren liquid posticies. The atatintical function which

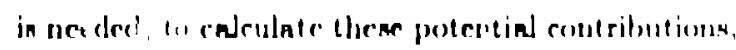
in the twe-phetirle correlation functiont. The Bulte

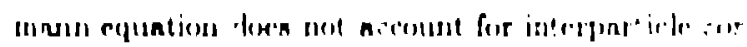

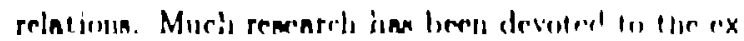

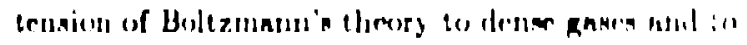
liquida. Wr note tlie vork of Enokerg. Which im dies

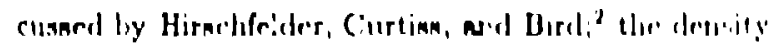

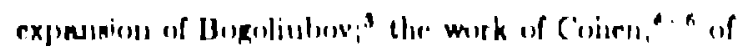

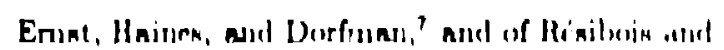

Debener," all showing that the density expention dexis not converge; and the establishment of global h theroreme for certuin syatrma by Résibos," nud by Karkheck, mn Beijeren, de Scheppere, and Sucll."0

The nature of a liquid, which is in cont rust to the nature of a gas, is that n given particle is in ennti. nous interactoon with its ueighbors. Henere the con crpt of collisions is not apperoj riate for a stutistirnl

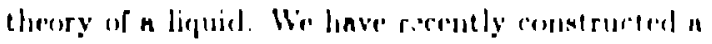

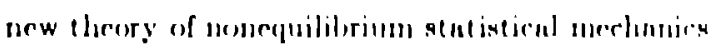
for a liguid. ${ }^{11,12}$ In the prenernt pinjer. we show that

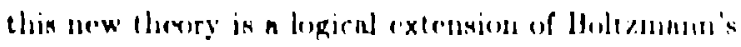
ther, ry:

\section{BOLTZMANN THFORN}

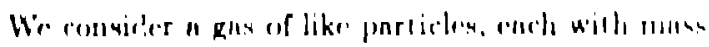

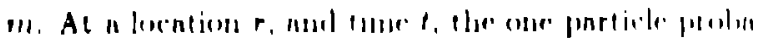

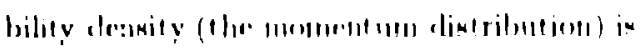
$f^{(1)}(r, p, 1)$. Noter r and p reptreseld verteres All ther

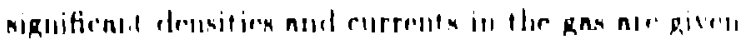

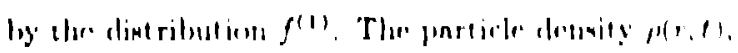
nut the fluid velocity e(r,t), nere given by

$$
\begin{aligned}
& n(r, p)-\int f^{(1)}(r, p, 1) d p
\end{aligned}
$$

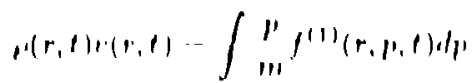


The tnergy per particle, in the local center-of-mass frame, is $e^{(1)}(r, t)$, where

$$
\rho(r, t) \epsilon^{(1)}(r, t)=\int \frac{[r-m e \cdot(r, t)]^{2}}{2 m} f^{(1)}(r, p, t) d p .
$$

The piessure tensor $P^{(1)}(r, t)$, and the energy current $J^{(1)}\left(r,{ }^{\prime}\right)$, are given by well-known formulas which we will rot exhibit here.

The Boltzmann equation is an evolution equation for the otatistical function $f^{(1)}(r, p, t)$. The irreversible aspect of this evolution is containcd in the collision in!egral $C(r, p, t)$, which wr will construct in a slightly unorthodox way: At a given $r, t$ in the gaw, there ure two-partivle collisions in which the particle momenta $p, p^{\prime}$ go to $\dot{p}, \dot{p}^{\prime}$. For a given phase-npace volume element $d \dot{p} d i^{\prime}$, the trassition rate is $x\left(p, p^{\prime} / \dot{p}, \dot{p}^{\prime}\right) d j w / \dot{p}^{\prime}$. $\chi\left(p, p^{\prime} / \dot{p}, \dot{p}^{\prime}\right)$ is invariant under the interrlinnge of $p, p^{\prime}$ with $\dot{p}, \hat{p}^{\prime}$, and $\lambda\left(p, p^{\prime} / \dot{p}, \hat{p}^{\prime}\right)$ contnine two $A$-functions as fartors: $\delta\left(p+p^{\prime}-\dot{p}-\hat{p}^{\prime}\right)$, representing conervation of momentum, and $\delta\left(p^{2}+p^{\prime 2}-\dot{p}^{2}-\hat{p}^{\prime 2}\right)$, reprearist ing conservation of enrrgy. Becaune of thr collsaims, particle pairn are entrring und lenving the pair dis tribution $f^{(1)}(r, p, t) f^{(1)}\left(r, p^{\prime}, t\right)$, and the net rate of chasage of thise pair dintribution in

$$
\begin{aligned}
& M\left(r, p, p^{\prime}, l\right)=\iint\left[f^{(1)}(r, j, t) f^{(1)}\left(r, j^{\prime}, t\right)\right. \\
& \left.-f^{(1)}(r, p, t) f^{(1)}\left(r, p^{\prime}, t\right)\right] \\
& \times \mathbf{p}\left(p, p^{\prime} / \dot{p}, \dot{p}^{\prime}\right) d p h l \dot{p}^{\prime} .
\end{aligned}
$$

hategration of this ower dp' given the collimional rate of changer of $p(r, f) f^{(1)}(r, p, f)$. But the collixionind rne of

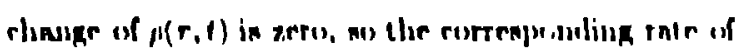

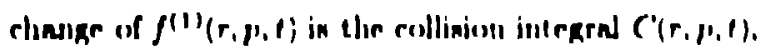
given ly

$$
p(r, l)\left(r^{\prime}(r, p, p)-\int R\left(r, \mu, p^{\prime}, l\right), p^{\prime} .\right.
$$

Ther Irnsasition rner $x$ in nimply terlntril en the collixions rtoman nertionn $n$.
The Boltzmann equation is

$$
\left(\frac{\partial}{\partial t}+\frac{p}{m} \cdot \Gamma_{r}\right) f^{(\prime \prime}(r, p, t)=C(r, p, t)
$$

where the term in $\Gamma$, is the drift tern (straming tern). The Boltzmann equation possesses tire follow. ing three important properties.

(a) For a general matcrial, the theory of continuum nechanics expresses, in local form, the well. known lawe of conservation of mass, of line'ar momerntum, and of rnergy. For a gas, where the densitic s and eurrents are given by the one-parti-le: contributions. the Boltzmasn equation yiclde the three local conservation. Inws.

(b) For a function $h(r, 1)$, which is the h-qunutity per particle al locncion $r$ and time $t$, the lorad $h$ there rem is

$$
\begin{aligned}
\frac{\partial \rho(r, t) h(r, t)}{\partial t}+\nabla_{r} \cdot[\mu(r, t) r(1, t) h(r, t) \\
+I(r, t)]=\Sigma(r, t)
\end{aligned}
$$

wheie $I(r)$ is the $h$ current, and $\Sigma(r, p)$ is the somrer function. $\Sigma(r, t)$ is a Linjunov functional, so thut $\Sigma(r, t) \leq 0$, with $\Sigma(r t)=0$ only at requilibrium.

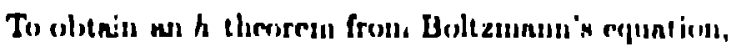
it in neresenry to ndel some informatiou, nnmerly the

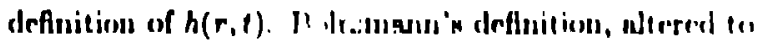

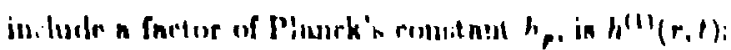

$$
n(r, l) h^{(1)}\left(r, l,-\int f^{(1)}(r, p, l)\left(n h_{r}^{\prime} f^{(1)}(r, p, l) d p,\right.\right.
$$

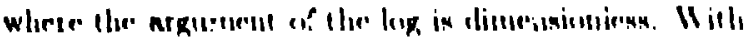

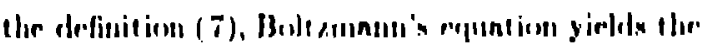
lornl $h$ thereren (bi).

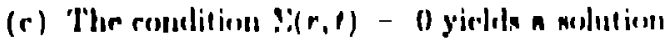
for thr muilihrium monnentum distributiun $\left.f_{n}^{(1)}, p\right)$. Taking inten acrount the know'll muilibrinm valuen of p.r, nud e, nuil elimiuntiug e in ensut of the incerse 
temperature $\beta, f_{0}^{(1)}(p)$ is uniquely determined to be the Boltzmann distribution:

$$
f_{0}^{(1)}(p)=\rho(\beta / 2 \pi m)^{3 / 2} c x p\left[-\beta(p-m v)^{2} / 2 m\right]
$$

\section{EXTENSION TO A LIQLID}

We no:s consider a liquid of like particles, interneting through the central potential $\phi(||$.$) , where s is the$ rector separation between two particles. The probalibiity density for a particle at $r-\frac{1}{2}$ s with momentum $p$, and sinultaneously a particle at $r+\frac{1}{2} s$ with momentum $p^{\prime}$, is $f^{(2)}\left(r-\frac{1}{2}, s, p, r+\frac{1}{2} s, p^{\prime}, t\right)$. From this, we define thr two-particle correlation function $q^{(2)}$ :

$$
\begin{aligned}
f^{(2)}\left(r-\frac{1}{2} s, p, r+\frac{t}{2} s, p^{\prime}, t\right) \\
\quad=f^{(1)}\left(r-\frac{t}{2} s, p, t\right) f^{(1)}\left(r+\frac{t}{s}, p^{\prime}, t\right) \\
\quad \times \gamma^{(2)}\left(r-\frac{1}{s} s, p, r+\frac{t}{t} s, p^{\prime}, t\right) .
\end{aligned}
$$

To construct a nimple evolution theory including iwoperticle correlation effectn, we will introduce two n!)proxinntions, which are discusaed in detnil in n longer paper. ${ }^{12}$ We asume that $f^{(1)}$ and $\gamma^{(2)}$ vary by ouly a sminll relntive anowut when they are tranalned through a dintance of order or less than the correlatim length, and we also neglert monentum correlations, i.r. neglect the momentum fependence of $\gamma^{(2)}$.

As a result of these npproximations, the theory ens br based on the two-particle probability druxity

$$
f_{a}^{(2)}\left(r, s, p, p^{\prime}, t\right)=f^{(1)}(r, p, t) f^{(1)}\left(r, p^{\prime}, t\right) g^{(2)}(r, \ldots, t),
$$

together with grewliente of $f^{(1)}$ nud $g^{(2)}$. Here $y^{(2)}$ in the moment um-nverngerl correlntion function:

$$
\begin{gathered}
\rho^{2}(r, t) g^{(c)}(r, n, t)=\iint f^{(1)}(r, p, t) f^{(1)}\left(r, p^{\prime}, t\right) \\
\times \gamma^{(2)}\left(r-t, p_{1}, r+t, n, p^{\prime}, t\right) d p d p^{\prime} .
\end{gathered}
$$

The functien $q^{(2)}(r, a, f)-1$ in lornl, i.r. it vasumber

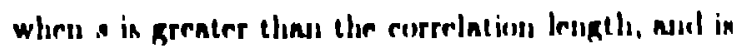
mortunalized according to

$$
\rho(r, t) \int\left[g^{(2)}(r, s, t)-1\right] d s=-1+a(r, t) .
$$

where $a(r, t)$ represents density fluctuations, $a(r, t)$ is positive, and $a(r, t)<1$ for a liq̧uid. In muny cares of liquid theory, it is not unreasonable to set $a=0 \mathrm{ks} \mathrm{n}$ frst approximation. The two-particle contributions to the energy and pressure, $e^{(2)}(r, t)$ and $P^{(2)}(r, l)$ respertively, are given by

$$
\begin{gathered}
e^{(2)}(r, t)=\frac{1}{2} \rho(r, t) \int \phi(|s|) g^{(d)}(r, s, t) d s, \\
P^{(2)}(r, t)=-\frac{1}{2} \rho^{2}(r, t) \int \phi^{\prime}(|s|) \frac{s s}{|s|} g^{(t)}(r, s, t) d, .
\end{gathered}
$$

where $\phi^{\prime}(|s|)=d_{\varphi}(|s|) ! d|s|$. From our approximations, it follows $J^{(2)}(r, t)=0$.

Let us next consider the irreversil. aspect of the evolution of a nonequilibrium liquid. This can be described in terms of effotive two-particle interactions, in which two partirles interact nut ay an imolnted pair, but an a pair immersed in a sen of backgroum! interartions. In ourh nn offective two particle inter-

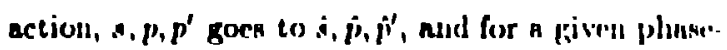

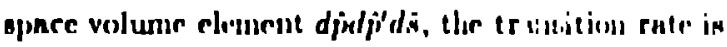

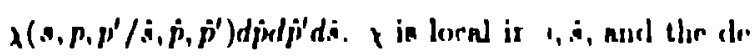
pendence of $\chi$ on $r, t$ in nuppremend fo $n$ !blorevineinu. Because of microncopic reversibility, $\left(1, p, p^{\prime} / \dot{j}, \dot{p}, p^{\prime}\right)$ is invarinut under the interchnegr of 11,1 with

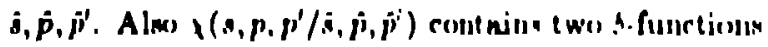
as factorn: $\lambda\left(p+p^{\prime}-\dot{p}-\hat{p}^{\prime}\right)$, reprenes li.ig romersint ion of monirutum, and $A(\omega-\dot{\omega})$, reprenet litig comarrint ien of the "energy of menn ferre," where

$$
w\left(r, A, p, p^{\prime}, 1\right)=\frac{p^{\prime}}{2 m}+\frac{p^{\prime 2}}{2 m}+u^{\prime \prime \prime}(2 n, r, n, p)
$$

$w^{(2)}(r, a, t)$ in the leocal perterntinl of mun: forer in the. nourquilibrium lipuid. "1.12 The import nut point in that, in mu'ronecopir corray conmervation within the

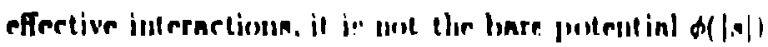


which enters, but the potential of mean force $w^{(2)}(r, s, t)$.

Because of the interactions, particles are entering and leaving the phese-space volume around $s, p_{1} p^{\prime}$, and the suet rate of change of $f_{0}^{(2)}\left(r, s, p, p^{\prime}, l\right)$ is

$$
\begin{aligned}
& F^{(2)}\left(r, s, p, p^{\prime}, t\right) \\
& =\iiint\left[f_{a}^{(2)}\left(r, \dot{s}, \dot{p}, \dot{p}^{\prime}, t\right)-f_{a}^{(2)}\left(r, s, p, p^{\prime}, t\right)\right] \\
& \times \times\left(s, p, p^{\prime} / \dot{s}, \dot{p}_{,} \dot{p}^{\prime}\right) d j d \dot{p}^{\prime} d \dot{s} .
\end{aligned}
$$

The corresponding rate of change of $f^{(1)}(r, p, t)$ is

$$
F^{(1)}(r, p, t)=\iint F^{(2)}\left(r, s, p, p^{\prime}, t\right) d p^{\prime} d,,
$$

and the corresponding rate of chan;ge of the quantity $f^{2}(r, t) g^{(2)}(r, s, t)$ is

$$
G^{(2)}(r, s, t)=\iint F^{(2)}\left(r, s, p, p^{\prime}, t\right) d p d p^{\prime} .
$$

Finaly, while the energy of mean force is conserved microseopically, within each effective two particle interaction, the total energy must be conserved macrosecpically, and this gives an integral condition sul $x$. which can be put in the form ${ }^{11,12}$

$$
\int\left[\phi(|s|)-w^{(2)}(r, s, t)\right] G^{(3)}(r, s, t) d s=0 .
$$

The extension of Bolezmanus theory to a lipuid is accoinplished by constructing two coupled evolution equations, one for $f^{(1)}(r, p, t)$ and one for $g^{(2)}(r, n, t)$. These equationn are:

$$
\begin{aligned}
& \left(\frac{\theta}{\partial !}+\frac{p}{m} \cdot \nabla_{r}+L(r, t) \cdot \nabla_{p}\right) f^{(1)}(r, p, t)=F^{(1)}(r, p, t) \\
& \begin{aligned}
\rho^{2}(r, t) & \left(\frac{\partial}{\partial t}+v(r, 1) \cdot \nabla_{r}+. \Gamma_{r}(r, t) \cdot \nabla_{0}\right) g^{(2)}(r, n, l) \\
& =G^{(2)}(r, n, t) .
\end{aligned}
\end{aligned}
$$

II (i9), $L(r, t)$ in t!e menu forer on a particle at r, t,

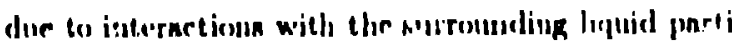
cles, nutl in given by

$$
\rho(r, t) L(r, t)=-\Gamma_{r} \cdot \rho^{(2)}(r, 1)
$$

In (20), the term in $\nabla_{r}$ is due to the drift together of particle pairs, and the term in $\nabla$, is due to the drift apart of particle pairs.

The coupled equntions (19) and (20) pouscs: the same importent properties an dises the Boltzmann equation, as noted in (a)-(c) below.

(a) When the energy, pressure, and energy current are given by the sum of one- and two-purticle contributions, then the local equations for consrrvation of particles, of liner moment urn, and of energy follow dirertly from (19) nusl (20).

(b) To prove an $h$ thesrem, we set

$$
\dot{n}(r, t)=h^{(1)}(r, t)+h^{(2)}(r, t)
$$

where $h^{(1)}(r, t)$ is the Boltzmunu form (7), and $h^{(3)}(r, t)$ in the nonrquilibrium extension of our liquid correlntional entropy, ${ }^{13,14}$

$$
h^{(2)}(r, t)=\frac{1}{i} p(r, t) \int g^{(2)}(r, s, t) \ln g^{(2)}(r, \ldots, t) d s .
$$

As a resule of our npproximatimus, $.^{\prime 2)}(r, 1)=0$. Then the local $h$ theorem, rquation (6). fillowe from the liquid evolution equations (16) and (2,1)

(c) Ther ryuilibrium solution, obenincel ly setting, $\Sigma(r, t)=0$, given agnin the Bult zimanu rxpression (8) for $f_{0}^{(1)}(p)$, and adwo giver

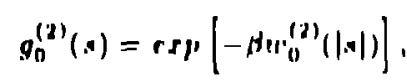

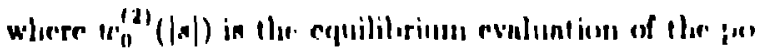
irilial of mens fores. The is the correct eppilibrium exprension for the correlation function $g_{11}^{(2)}(x)$.

An a flund note, it lins brentu nleown that, for a nenr equilibriun nituntiom, our atutisticnl rvelution therery reproducen preriarly the irresernible thermenlyunmies

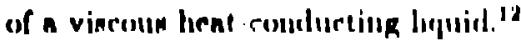




\section{REFERENCES}

1. L. Boltzmann, Wien. Ber. 66 (1872) 275.

2. J. O. Hirsehfelder, C. F. Curtiss, and R. B. Bird, Molecular Theory of Geses and Liquids (Wiley, New York, 1954) $\$ 9.3$.

3. N. N. Bogoliubov, in: Studies in Statistical Mechanics, Vol. 1, eds. J. DeBoer and G. E. Uhlenbeck (North-Holland, Amsterdam, 1962) p. 1; translated from N. N. Bogoliubov, J. Phys. (Moscow) 10 (1946) 256, 265.

4. E. G. D. Cohen, in: Tranaport Phenomena in Fluids, ed. H. J. M. Hanley (Dekker, New York, 1069) 157.

5. E. G. D. Cohen, in: Lectures in Theortich Physics, Vol. 9C, ed. W. E. Brittin (Gordon and Breach, New York, 1967) 279.
6. E. G. D. Cohen, in: Fundamental Problenus in Statistiral Mechanies II, ed. E. G. D. Cohen (NorthHolland, Amsterdan, 1968) 228.

7. M. H. Emst, L. K. Haines, and J. R. Dorfman, Rev. Mod. Phys. 41 (1969) 290.

8. P. Résibois and M. De Leener, Clussical Kinetic Theory of Fluids (Wiley, New York, 1977) Ch. 10. 9. P. Résibois, J. Stat. Phy's. 19 (1978) 593.

10. J. Karkheck, H. wn Beijeren, S. de Schepper, and G. Stell, Phys. Rrv. 432 (1985) 2517.

11. D. C. Wallace, Phys. Rev. A35 (1987) 4334.

12. D. C. Wallace, Nonequilibriun Statistical Mechanics of a Dense Fluid Il. The Thersy without Momentun Correlacions, Phys. Mev, A (submitted).

i3. D. C. Wallace, J. Chen. Phys. 8 i (1987) 2282.

15 D. C. Wallare, Phys. Lett. 122A (198:) 418. 